\title{
CARACTERÍSTICAS E PROPRIEDADES POZOLÂNICAS DE ARENITOS OPALINOS DASERRA DE ITAQUERI, SP
}

\author{
Tarcísio José MONTANHEIRO \\ Jorge Kazuo YAMAMOTO \\ Yushiro KIHARA
}

\begin{abstract}
RESUMO
Os arenitos opalinos da Formação Itaqueri são qualificados como pozolana natural devido aos seus índices de atividade pozolânica (79 e 90\%) estarem acima do limite (75\%) estabelecido pela norma brasileira (ABNT, 1992a). Eles foram identificados na região de Itaqueri da Serra, Estado de São Paulo, em trabalhos rotineiros de prospecção estratégica. Os atributos intrínsecos dessas rochas foram identificados e, analisados, denotam uma associação mineralógica, litoestratigráfica e tectônica, que constituem importantes guias prospectivos da mineralização de opala na Bacia Sedimentar do Paraná.

Além de discutir a classificação dos materiais pozolânicos quanto à origem e enfatizar a importância da Formação Itaqueri como metalotecto para depósitos pozolânicos, são examinados no contexto desse trabalho os procedimentos usuais de prospecção estratégica de pozolanas naturais, as técnicas analíticas que pré-qualificam e quantificam esses materiais e os difratogramas de raios $\mathrm{X}$ que exibem a neoformação de C-S-H em pastas de $\mathrm{Ca}(\mathrm{OH})_{2}$ e arenito opalino.

As qualidades tecnológicas e, principalmente, os benefícios ambientais e econômicos do uso de pozolanas no cimento Portland com adição (elas reduzem a emissão de $440 \mathrm{Kg}$ de $\mathrm{CO}_{2}$ por tonelada de calcário calcinado e agregam lucro financeiro da ordem de $20 \%$ no produto final) também são aqui analisados e comparados.

Palavras-chave: pozolana; arenito opalino; Formação Itaqueri.
\end{abstract}

\section{ABSTRACT}

Opaline sandstones of the Itaqueri Formation are considered natural pozzolans because their reaction with cement yields pozzolanic reactivity indexes in the range of $79 \%$ and $90 \%$, which is much higher than the lower limit of $75 \%$ established by Brazilian standards (ABNT, 1992a). These rocks have been found during exploration campaigns in the region of Itaqueri da Serra - São Paulo State, Brazil. Analytical work revealed their intrinsic mineralogical attributes that, in addition to lithostratigraphic and tectonic characteristics, give important prospection guidelines for opal mineralization in the Paraná Basin.

This paper discusses the classification of natural pozzolans according to their origin and emphasizes the importance of the Itaqueri Formation as a metallotect for pozzolanic deposits. The strategies for prospection of natural pozzolans are also examined, as well as the analytical techniques that pre-qualify and quantify these materials, such as X-ray diffraction that depicts the neoformation of C-S-H resulting from the chemical reaction between $\mathrm{Ca}(\mathrm{OH})_{2}$ paste and opaline sandstone after 7-day curing.

The technological and mainly environmental and economical benefits of using pozzolans in cement blending are analyzed and compared here. There is the emission of up to $0.44 \mathrm{t}$ of $\mathrm{CO}_{2}$ per ton of calcinated limestone and savings of approximately $20 \%$ are gained in the production of blended Portland cement.

Keywords: pozzolan; opaline sandstone; Itaqueri Formation 


\section{INTRODUÇÃO}

A moagem de pozolana e clínquer Portland produz aglomerantes hidráulicos especiais definidos internacionalmente como cimentos Portland compostos. As suas características particulares, tecnologicamente benéficas à indústria de concreto, provêm da adição adequada de pozolanas ao clínquer.

Aos benefícios já referidos por MIELENZ et al. (1951), ainda poderíamos acrescentar as vantagens econômicas, ambientais e geológicas citadas por YAMAMOTO et al. (1997), se considerarmos estes dois fatores: primeiro, o custo inferior da pozolana em relação ao clínquer Portland e, segundo, a produção total de cimento de uma fábrica.
A fabricação de uma tonelagem de clínquer continuará a exigir a mesma quantidade de farinha, os mesmos gastos de consumo energético e a mesma geração e emissão de $\mathrm{CO}_{2}$. Entretanto, a substituição de uma fração do clínquer por pozolana produzirá mais cimento - que é o produto final - com a mesma tonelagem de clínquer. Indiretamente estará sendo fabricado um cimento composto de menor custo, e com baixo consumo energético. Do mesmo modo, utilizando-se menos clínquer na produção de uma tonelagem de cimento com adição de pozolana, a emissão de $\mathrm{CO}_{2}$ por tonelagem desse tipo de cimento também será menor. Dessa forma se contribuirá para o estabelecimento de um modelo de desenvolvimento sustentável, uma vez que reciclando resíduos industriais com propriedades pozolânicas

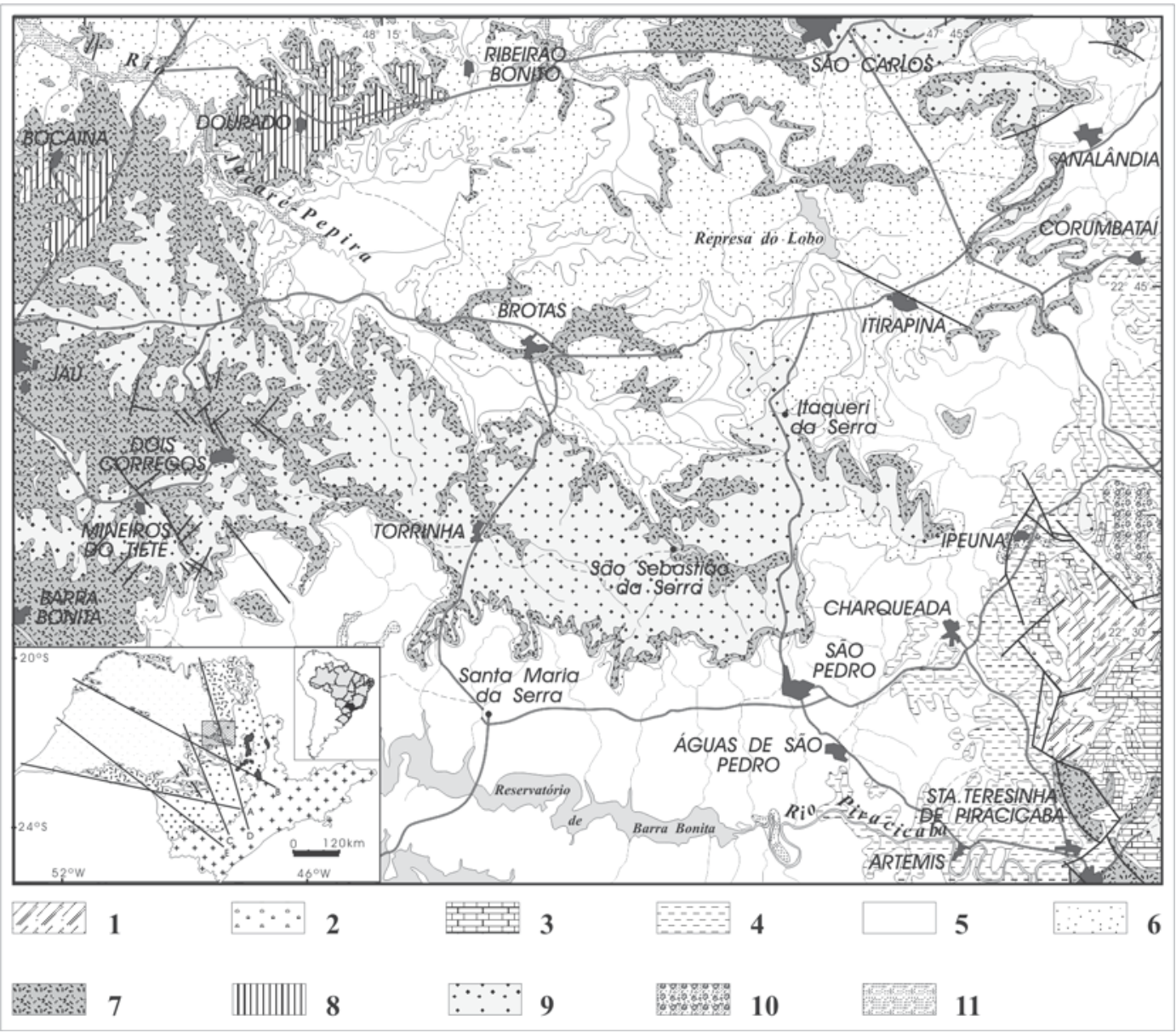

FIGURA 1 - Mapa geológico da área estudada (UNESP- Rio Claro 1982). 1. Subgrupo Itararé; 2. Formação Tatuí; 3. Formação Irati; 4. Formação Corumbataí; 5. Formação Pirambóia; 6. Formação Botucatu; 7. Formação Serra Geral; 8. Formação Adamantina; 9. Formação Itaqueri; 10. Formação Rio Claro; 11. Depósitos Aluviais; A. Alinhamento do Rio Paranapanema; B. Alinhamento Estrutural do Tietê; C. Alinhamento Ibitinga-Botucatu; D. Alinhamento do Rio MojiGuaçu. 
para a fabricação de cimento implicará, conseqüentemente, menor consumo de matéria prima calcária e argilosa. Assim, da parte da Geologia, esse procedimento tanto pode preservar os grandes depósitos carbonáticos como viabilizar os outros considerados pequenos ou mal localizados, uma vez que se estarão agregando novos valores econômicos a minerais e rochas considerados estéreis ou inservíveis.

Dentre essas substâncias naturais com características pozolânicas, ou seja, portadoras de componentes minerais ativos para uma reação pozolânica, identificadas em MONTANHEIRO (1999) durante trabalho de prospecção estratégica no Estado de São Paulo, a opala se destaca como uma das principais.

Neste trabalho são apresentadas as características e propriedades pozolânicas de arenitos opalinos da Serra do Itaqueri (SP), ocorrência localizada nos arredores da torre da EMBRATEL (Empresa Brasileira de Telecomunicações), $4 \mathrm{Km}$ ao norte do centro urbano de Itaqueri da Serra e distante 70 Km de Piracicaba (Figura 1). O acesso ao local se faz pela estrada asfaltada intermunicipal "Ulisses Guimarães” que liga a cidade de São Pedro - Itaqueri da Serra - Itaqueri da Serra - Itirapina, passando pela torre.

\section{CONSIDERAÇÕES GERAIS SOBRE MATERIAIS POZOLÂNICOS}

Pozolanas são substâncias naturais ou artificiais, de composição silicosa ou sílico-aluminosa, que, não sendo por si sós cimentícias, reagem, porém, com hidróxido de cálcio à temperatura ambiente resultando em compostos com propriedades cimentícias.

Os materiais pozolânicos podem ser classificados em dois grandes grupos: naturais e artificiais, se bem que existam controvérsias no tocante à classificação de certos tipos de pozolanas, como das argilas calcinadas que, segundo alguns autores são dadas como naturais e, segundo outros, como artifi- ciais. O ponto crucial da questão está em classificar uma rocha cujas propriedades pozolânicas são realçadas com o tratamento térmico. MALQUORI (1960), MASSAZZA (1976), ABNT (1991a) e KITSOPOULOS \& DUNHAM (1996), entre outros, inclusive os presentes autores, classificam como pozolanas naturais todas as rochas portadoras de atividade pozolânica natural . Por outro lado, MIELENZ et al. (1951), MEHTA(1987) e ACI (1994), entre outros autores, admitem como pozolanas naturais também os produtos da calcinação dessas rochas. Se alguma controvérsia persiste quanto à abrangência classificatória das pozolanas naturais, ela inexiste no tocante à classificação, como pozolanas artificiais, aqueles subprodutos industriais que são de natureza artificial.

No tocante à origem, posicionando-se argilitos naturalmente pozolânicos (ex: as argilas cauliníticas mal cristalizadas da região do Estado da Paraíba) para um grupo e as argilas calcinadas (metacaulinita) para o outro, pode-se classificar os materiais pozolânicos conforme apresentado na Tabela 1.

Nesse ponto, dependendo de sua origem, as pozolanas naturais apresentam variações consideráveis nas suas propriedades à proporção que variam os componentes ativos das rochas, suas características físicas e mineralógicas. A forma, finura, distribuição do tamanho das partículas, densidade e composição mineralógica das pozolanas naturais são também fatores que influenciam na reação pozolânica e, conseqüentemente, no resfriamento e no desenvolvimento da resistência do concreto (ACI 1994). A reação pozolânica se desencadeia devido à reatividade da sílica e da alumina ao hidróxido de cálcio, pela fraqueza e instabilidade de suas ligações estruturais no material original - caso do vidro vulcânico ou das argilas calcinadas (MALQUORI 1960).

Tomando como referência a composição química e mineralógica das próprias pozolanas, MIELENZ et al. (1951) as classificaram quanto à sua atividade-tipo (Tabela 2), a qual foi expressa pela

TABELA 1 - Classificação dos materiais pozolânicos quanto à origem.

\begin{tabular}{ll}
\hline \multicolumn{1}{c}{ Pozolana Natural } & \multicolumn{1}{c}{ Pozolana Artificial } \\
\hline Rochas vulcânicas ácidas & Escórias ácidas de alto forno \\
Tufos vulcânicos & Cinzas volantes \\
Terras diatomáceas & $\begin{array}{l}\text { Resíduos argilosos de folhelhos betuminosos } \\
\text { após extração } \\
\end{array}$ \\
Arenitos e folhelhos opalinos & Microssílica \\
Argilitos de argilas mal cristalizadas & Argilas calcinadas (metacaulinita) \\
\hline
\end{tabular}


afinidade e intensidade de reação em presença da água, do hidróxido de cálcio com o tipo de componente ativo presente no compósito mineralógico, independentemente da origem da rocha.

Nesta classificação foram colocadas em destaque as pozolanas de Atividade-Tipo-2 incluindose diatomitos, “cherts” e folhelhos opalinos devido à atividade da opala, os quais se comportam como dos mais reativos de todas as pozolanas naturais.

TABELA 2 - Classificação de materiais pozolânicos, conforme a sua atividade-tipo (MIELENZ et al. 1951).

\begin{tabular}{cl}
\hline Atividade-Tipo & \multicolumn{1}{c}{ Componente Ativo } \\
\hline 1 & Vidro vulcânico \\
2 & Opala \\
3 & Argilas \\
3a & caulinita \\
3b & montmorillonita \\
3c & illita \\
3d & camada mista com vermiculita \\
3e & paligorskita \\
4 & Zeólita \\
5 & Óxidos de alumínio hidratados \\
6 & Não pozolânico \\
\hline
\end{tabular}

\section{FORMAÇÃO ITAQUERI: CONTEXTO GEOLÓGICO E TECTÔNICO}

A prospecção estratégica de matéria-prima pozolânica na Bacia do Paraná, dentro do Estado de São Paulo, deve ser direcionada para unidades geológicas que concentram componentes pozolânicos ativos, como vidro vulcânico, opala, argilas e zeólitas.

Ao longo deste estudo destacamos, pois, a Formação Itaqueri que ostenta depósitos volumosos de argila e arenitos ricos em opala e calcedônia, constituindo um possível metalotecto litoestratigráfico concentrador de depósito pozolânico.

A Formação Itaqueri distribui-se na porção central do Estado de São Paulo, capeando as serras de São Pedro, Itaqueri e platô de São Carlos, preservadas, em grande parte por rochas básicas da Formação Serra Geral e arenitos mesozóicos silicificados da Formação Botucatu (BÓSIO 1972), os quais foram reunidos na Superseqüência Gondwânica III por MILANI (1997).

Este pacote magmático-sedimentar recobre os depósitos das formações Pirambóia e Corumbataí da Superseqüência Gondwânica I (MILANI 1997), e marca, na área de estudo, os limites entre as cuestas basálticas e o planalto ocidental.

A Formação Itaqueri, de idade paleocênicaeocênica, recobre o topo de escarpas que atingem altitudes aproximadamente de 1000 m e está assentada sobre superfície regular, desenvolvida nos basaltos da Formação Serra Geral ou diretamente sobre a Formação Botucatu - quando da ausência dos basaltos da Formação Serra Geral - após erosão pós-basáltica que promoveu aplainamento de todas as irregularidades deixadas pelas atividades tectônicas precedentes (RICCOMINI 1995 e 1997). Sua constituição mais constante é de depósitos rudáceos (conglomerados com clastos derivados predominantemente de rochas básicas referíveis ao magmatismo Serra Geral), arenitos e lamitos interpretados como leques aluviais sedimentados sob condições de média a alta energia (MELO 1995; RICCOMINI 1997) provavelmente durante a evolução da Superfície de Aplainamento Japi (PONÇANO et al. 1982).

No quadro que AMARAL (1977) e RICCOMINI (1995 e 1997) estabeleceram caracterizando a evolução das unidades sedimentares na Bacia do Paraná dentro do Estado de São Paulo, e, mais particularmente da Formação Itaqueri, pode-se observar que elas estiveram submetidas a intensas movimentações e deformações relacionadas às megaestruturas de direções WNW, NW e NNW. Estas estruturas estabeleceram um controle sobre a morfologia atual dos platôs que preservaram os depósitos da Formação Itaqueri e possibilitaram, ainda, a percolação de fluídos hidrotermais para silicificação penecontemporânea dos sedimentos arenosos cimentados com opala e calcedônia.

\section{ARENITOS OPALINOS DA FORMAÇÃO ITAQUERI}

Os arenitos opalinos, que constituem objeto deste estudo (Figura 2), são rochas compactas, maciças e duras que ocorrem como blocos, assim como afloram em corte da estrada de acesso à torre da Embratel, numa área de aproximadamente $20.000 \mathrm{~m}^{2}$ a qual se destaca como um morrote de aproximadamente 50 metros de altura.

Os arenitos são mal selecionados, de granulação variada e apresentam, freqüentemente, grânulos dispersos numa matriz fina. Sua composição mineralógica é dada predominantemente por quartzo e, secundariamente, por turmalina e feldspatos. O cimento, característico de um proces- 

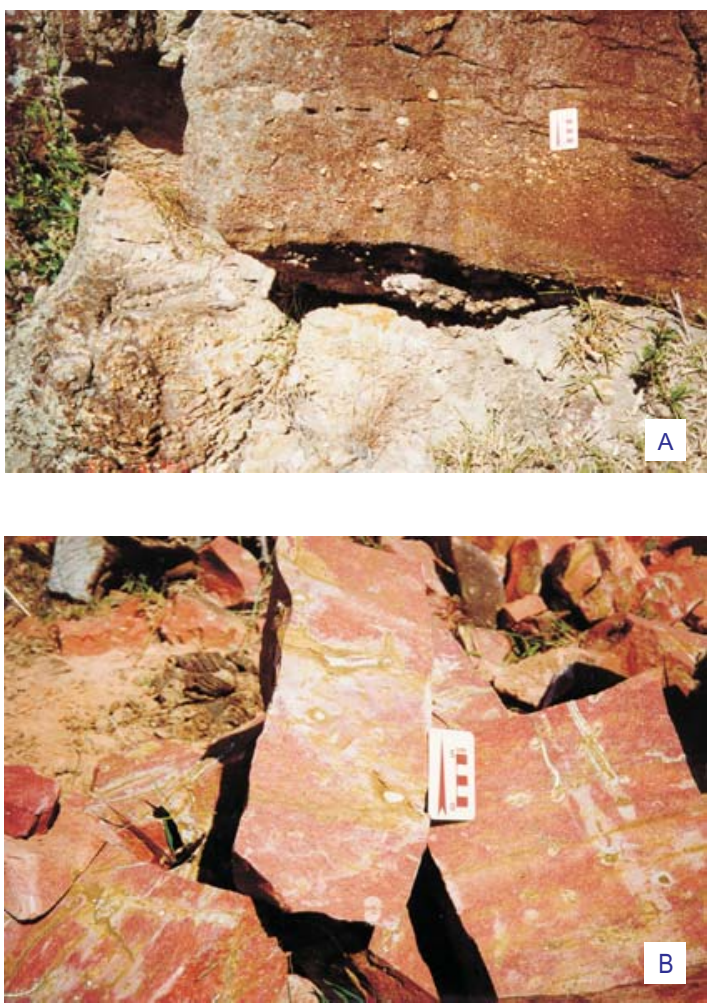

FIGURA 2 - Arenito conglomerático silicificado (A) e arenito opalífero (B) da Formação Itaqueri. Calcedônia secundária preenche fraturamento da massa opalina em B. Torre da Embratel, estrada Ulisses Guimarães, em Itaqueri da Serra, São Paulo.

so de silicificação intersticial, é composto por calcedônia e opala. Nota-se ainda em algumas partes no afloramento do arenito que a opala (ou calcedônia) constitui, às vezes, a componente principal da rocha ao passo que calcedônia secundária e quartzo não só preenchem fraturas de porções da rocha predominantemente opalinas e de arenitos silicificados, como também cimentam as porções clásticas. COIMBRA et al. (1981) salientam, em descrição microscópica, que "as evidentes feições de má seleção e do mal arredondamento dos grãos induzem a classificar essas rochas como texturalmente imaturas".

COIMBRA et al. (1981) e RICCOMINI (1995, 1997) verificaram que a Formação Itaqueri, nesta região, é seccionada pelos alinhamentos estruturais do Rio Tietê(NW), Moji-Guaçu (NMW) e São CarlosLeme (WNW). COIMBRA et al. (1981) descreveram que os processos de silicificação dos arenitos e conglomerados da Formação Itaqueri estariam associados à atividade de natureza hidrotermal, simultânea à sedimentação clástica. Segundo estes últimos au- tores, a opala seria proveniente de águas termais ricas em sílica, que teriam penetrado por fraturas em zonas de intersecção dos dois grandes alinhamentos estruturais: o primeiro - Alinhamento do Rio Tietê - de direção do N60W (sistema IpeúnaPiracicaba-Rio das Pedras) e o outro - Alinhamento do Rio Moji-Guaçu - de direção N20W, denotando um controle tectônico de mineralização.

\section{MATERIAIS E MÉTODOS}

Os trabalhos desenvolvidos durante um programa de prospecção superficial para materiais pozolânicos na porção interna da Bacia do Paraná (MONTANHEIRO 1999), no Estado de São Paulo, identificaram extensos afloramentos de arenitos e conglomerados opalinos em um alto topográfico da Serra do Itaqueri. Foram coletadas para o estudo de suas características físico-químicas e geológicas três amostras volumétricas representativas cuja composição química se encontra na Tabela 3. As feições texturais e morfológicas de grãos e sedimentos foram estudadas em microscópio petrográfico e microscopia eletrônica de varredura, conforme está apresentado nas Tabelas 4 e 5 e ilustrado pelas fotomicrografias da Figura 3 e imagens da Figura 4.

Na interpretação da análise de rocha total via difratometria de raios $\mathrm{X}$ diagnosticou-se uma associação mineralógica formada predominantemente pelo quartzo e secundariamente por feldspatos e caulinita. O difratograma mostra na faixa $2 \theta$ - entre 20 a $24^{\circ}$ (Figura 5) - que a rocha estudada contém um halo de material amorfo indicativo da presença de uma substância amorfa junto com substâncias cristalinas (quartzo, feldspatos e caulinita), possivelmente sílica amorfa, identificada como opala.

\section{MÉTODOS EXPERIMENTAIS}

Apesar da composição mineralógica ter sido estabelecida em amostras pontuais do afloramento, todos os ensaios para caracterização e confirmação da atividade pozolânica foram executados com amostras volumétricas que compunham uma massa equivalente a $15 \mathrm{Kg}$.

Depois de coletados, os arenitos opalinos foram processados com objetivo de homogeneizar e reduzir a quantidade de amostra a fim de que nas análises pudessem espelhar adequadamente a unidade litológica da Formação Itaqueri. Nesta sequêência de operações, as amostras passaram por britador de mandíbulas, moagem em disco de friç̧ão e pul- 
Revista do Instituto Geológico, São Paulo, 23(1), 13-24, 2002.

TABELA 3 - Componentes químicos de amostras representativas dos arenitos silicificados. Teor dos principais óxidos em \% determinados pelo método ICP (ppc = perda ao fogo em \%; n.a. = não analisado).

\begin{tabular}{lcccccccccc}
\hline AMOSTRA & $\mathrm{PPC}$ & $\mathrm{SiO}_{2}$ & $\mathrm{Al}_{2} \mathrm{O}_{3}$ & $\mathrm{Fe}_{2} \mathrm{O}_{3}$ & $\mathrm{CaO}$ & $\mathrm{MgO}$ & $\mathrm{Na}_{2} \mathrm{O}$ & $\mathrm{K}_{2} \mathrm{O}$ & $\mathrm{MnO}$ & $\mathrm{TiO}_{2}$ \\
\hline TM-100 & 4,61 & 78,45 & 9,94 & 4,32 & 0,21 & 0,07 & 0,04 & 1,79 & 0,02 & 0,27 \\
TM-101 & 1,31 & 96,57 & 0,75 & 0,82 & 0,14 & $-0,01$ & -0.01 & 0,18 & 0,06 & 0,03 \\
TM-102 & 0,88 & 96,41 & 0,64 & 1,76 & 0,12 & 0.02 & $-0,01$ & 0,13 & 0,02 & 0,04 \\
\hline
\end{tabular}
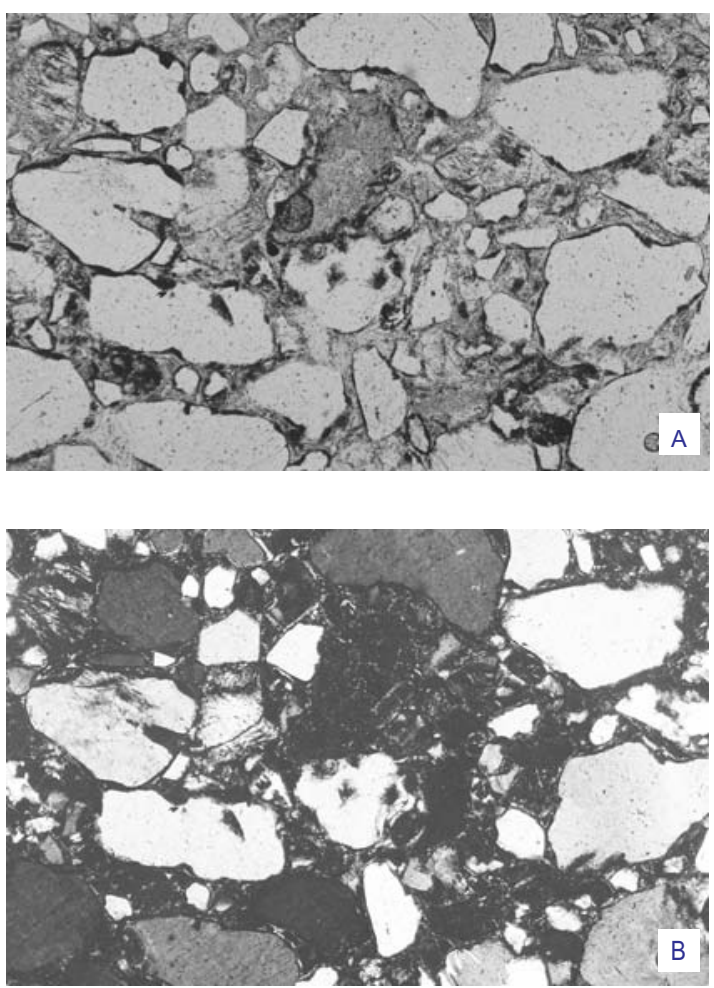

FIGURA 3 - Fotomicrografias de arenito opalino - “chert” - (amostra TM-101), mostrando cimento opalino isótropo. (A) polarizadores paralelos; (B) polarizadores cruzados. O lado menor da foto corresponde a $0,85 \mathrm{~mm}$.

verização em moinhos de bola, até se obter a finura necessária para os ensaios de pozolanicidade. No caso desse estudo, a peneira inicial foi a 325 (45 micra) obedecendo às normas da finura por peneiramento (ABNT, 1991b e ASTM, 1997).

Foram executados dois tipos de ensaios para confirmação da atividade pozolânica. Por difração de raios $\mathrm{X}$ identificaram-se os compostos químicos neoformados numa pasta de arenito opalino $+\mathrm{cal}$; e, noutro ensaio, o índice de resistência à compressão da mistura cimento + arenito.

Outras características físicas do material, impor-
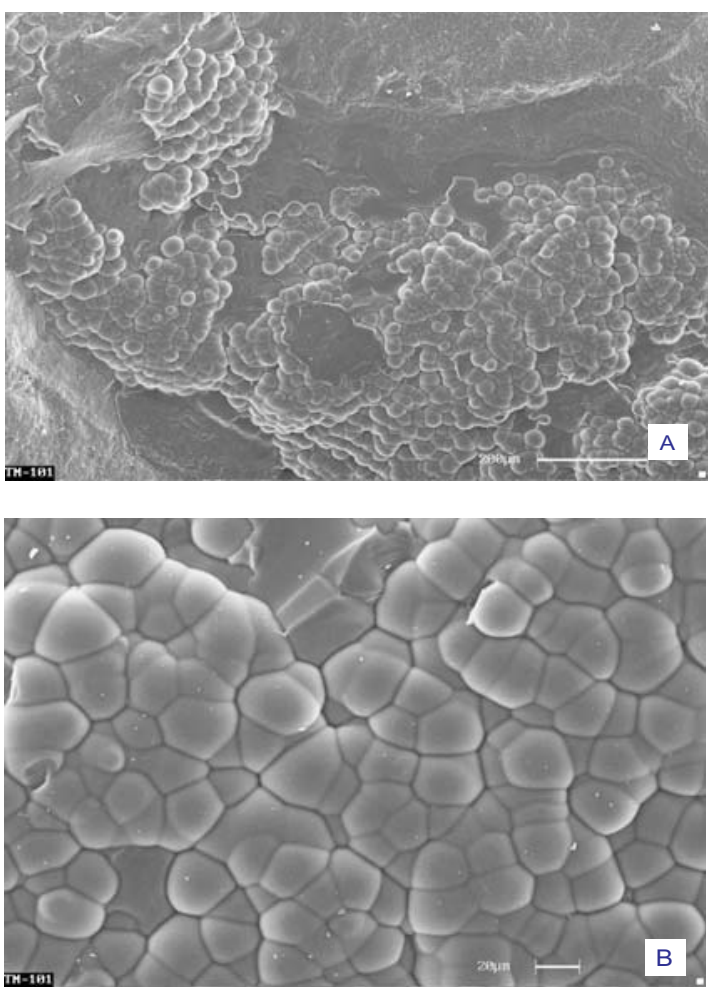

FIGURA 4 - Imagens obtidas ao microscópio eletrônico de varredura. (A) Aspecto geral das formas botrioidais da opala (amostra TM-101); (B) detalhe da imagem anterior.

tantes para a atividade pozolânica, foram massa específica e área específica determinadas, respectivamente, segundo as normas brasileiras ABNT (1989 e 1996).

O primeiro ensaio teve a finalidade de confirmar os produtos da reação pozolânica gerados numa pasta de hidróxido de cálcio com arenito opalino. Esta pasta foi feita mantendo-se a proporção em massa de uma parte de hidróxido de cálcio para duas partes de arenito opalino. A cura da pasta assim obtida foi feita em estufa à temperatura de $30^{\circ} \mathrm{C}$ durante 7 dias.

O segundo ensaio consistiu na determinação da atividade pozolânica com cimento obedecendo à nor- 
TABELA 4 - Descrição petrográfica detalhada de amostras selecionadas para ensaios de pozolanicidade.

\begin{tabular}{|c|c|c|}
\hline CLASSIFICAÇÃO & AMOSTRA & DESCRIÇÃO PETROGRÁFICA \\
\hline $\begin{array}{l}\text { Arenito (opalino) } \\
\text { arcosiano }\end{array}$ & TM-100 & $\begin{array}{l}\text { Na lâmina estudada observa-se que a rocha é composta predominan- } \\
\text { temente por quartzo ( } 75 \% \text { ); microclínio (7\%); plagioclásio (1\%); } \\
\text { muscovita/sericita e turmalina ( } 2 \%) \text {; calcedônia, opala e hidróxido de } \\
\text { ferro (15\%); biotita (tr) e zircão (tr). } \\
\text { A acumulação desses minerais mostra uma textura clástica } \\
\text { terrígena. As partículas são de granulometria muito fina a grossa } \\
\text { com a presença de grânulos de quartzo policristalino e grânulos } \\
\text { de microclínio. O tamanho dos grãos de quartzo varia de } 0,05 \mathrm{~mm} \\
\text { até } 1 \text { milímetro mas predominam aqueles monocristalinos meno- } \\
\text { res do que } 0,3 \text { mm. Grânulos de microclínio apresentam tamanho } \\
\text { de até } 2,5 \text { mm. A variação granulométrica evidencia o mau } \\
\text { selecionamento da rocha. } \\
\text { O grau de arredondamento dos grãos varia de angulosos a sub-arre- } \\
\text { dondados com predominância dos grãos angulosos a quase-angulo- } \\
\text { sos. A presença de feldspatos e o mau arredondamento evidenciam } \\
\text { imaturidade mineralógica e textural. } \\
\text { O preenchimento intergranular é um cimento composto por hidróxido } \\
\text { de ferro e sílica criptocristalina formada por calcedônia e opala, com } \\
\text { predomínio da calcedônia. Opala e hidróxido de ferro envolvem os } \\
\text { grãos da rocha ao passo que, na maioria das vezes, os poros foram } \\
\text { preenchidos por calcedônia fibrosa. Não se observam processos de } \\
\text { substituição (digestão de clastos), fato que torna evidente ter-se } \\
\text { opala depositado concomitantemente com os sedimentos. }\end{array}$ \\
\hline
\end{tabular}

Arenito com calcedônia - "chert"
TM-101

\begin{abstract}
A rocha estudada em lâmina delgada possui uma composição mineral formada pelos seguintes componentes principais: calcedônia (85\%); quartzo "dente de cão" (10\%) e quartzo clástico (5\%).O arranjo e a forma dos constituintes não cristalinos e cristalinos mostram uma textura não clástica sem a presença das relações de fábrica. O tamanho dos grãos de quartzo clástico no eixo maior é de até $0,5 \mathrm{~mm}$, mas predominam os grãos médios de $0,07 \mathrm{~mm}$. A evidente variação granulométrica caracteriza uma rocha mal selecionada. O grau de arredondamento dos grãos varia de sub-arredondado a anguloso. A massa predominante de calcedônia na rocha apresenta poros e espaços com opala. Inclui, muito provavelmente alguma sílica amorfa, quartzo criptocristalino e microcristalino e, certamente, impurezas como o hidróxido de ferro, que mancham e mosqueam também as opalas. Amígdalas mostram calcedônia fibrorradiada a criptogranular. A opala é sílica amorfa com um forte relêvo negativo, e, na luz polarizada, é sensivelmente isótropa.Os grãos se dispôem na rocha de tal modo que simulam estar flutuando no material diagenético recristalizado. Os aspectos microscópicos estudados permitem sugerir uma diagênese por reprecipitação de origem química e classificar a rocha como "chert".
\end{abstract}

ma brasileira ABNT (1992b). Neste ensaio preparam-se duas argamassas, conforme as quantidades recomendadas, para a moldagem de três corpos de prova cilíndricos de 50 mm de diâmetro por $100 \mathrm{~mm}$ de altura (Tabela 6); onde $\delta_{\text {poz }}$ e $\delta_{\text {cim }}$ são, respectivamente, as massas específicas do material pozolânico e do cimento, $\mathrm{X}$ e Y são as quantidades de água necessárias para produzir índices de consistência de (225 \pm 5 ) mm.
O índice de atividade pozolânica (IAP) com cimento Portland é definido por:

$$
\mathrm{IAP}=\frac{f_{c B}}{f_{c A}} .100(\%)
$$

onde $\mathrm{f}_{\mathrm{CB}}$ é a resistência média, aos 28 dias, dos corpos de prova moldados com cimento e material 
TABELA 5 - Resultados das análises mineralógicas por difração de raios X em arenito opalino (n.a. = não analisado; $\mathrm{Q}$ = quartzo; $\mathrm{F}$ = feldspato; $\mathrm{K}$ = caulinita).

\begin{tabular}{cccc}
\hline $\begin{array}{c}\text { UNIDADE } \\
\text { AMOSTRADA }\end{array}$ & AMOSTRA & DESCRIÇAOAOSUCINTA & $\begin{array}{c}\text { MINERALOGIA } \\
\text { PRINCIPAL }\end{array}$ \\
\hline Formação Itaqueri & TM-100 & arenito silicificado com opala - Serra do Itaqueri & Q; F; K \\
Formação Itaqueri & TM-101 & calcedônia + opala - Serra do Itaqueri & Q \\
Formação Itaqueri & TM-102 & calcedônia + opala - Serra do Itaqueri & n.a. \\
\hline
\end{tabular}

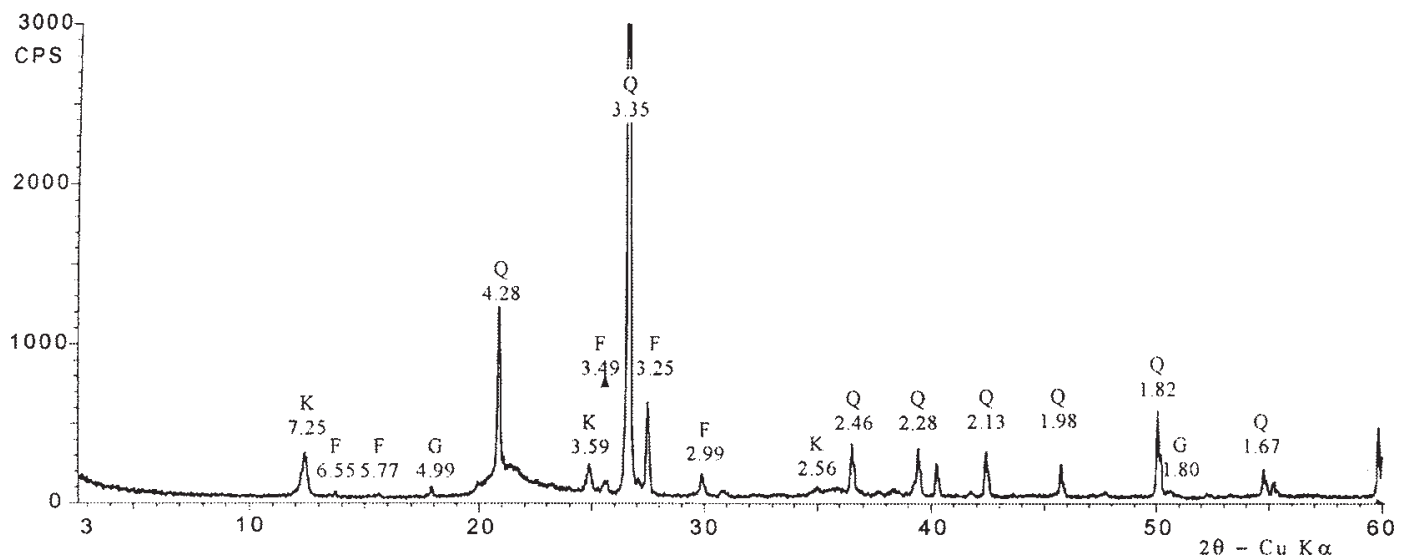

FIGURA 5 - Difratograma de raios X obtido para amostra total de arenito opalino (amostra TM-100), mostrando uma banda de material amorfo no intervalo $2 \theta$ entre 20 a $24^{\circ}$.

pozolânico (argamassa B), e $\mathrm{f}_{\mathrm{cA}}$ é a resistência média, aos 28 dias, dos corpos de prova moldados só com cimento (argamassa A). Anorma brasileira ABNT (1992a) prescreve valores de índices mínimos para atividade pozolânica com cimento Portland de 75\% e a água requerida, no máximo 115\%, para o caso de pozolanas classe $\mathrm{N}$ (pozolanas naturais e artificiais).

\section{RESULTADOS}

Os difratogramas de raios $\mathrm{X}$ das pastas de hidróxido de cálcio e pozolanas (amostras TM-100 e TM-101) estão representados na Figura 6.

Na Figura 6, observa-se que as pastas curadas exibem claramente a neoformação de silicato de cálcio hidratado (C-S-H) resultado da reação pozolânica nos seguintes intervalos 20: $10-11^{\circ}$ e $29-30^{\circ}$. Além disso, é possível observar também que os picos do hidróxido de cálcio ainda se apresentam nas pastas curadas, porém com menor intensidade devido ao seu consumo pela reação pozolânica. Os componentes neoformados encontram-se identificados na Tabela 7 .
Os resultados da caracterização física dos materiais estudados, como também o índice médio da resistência à compressão dos corpos de prova submetidos aos ensaios de atividade pozolânica com cal e com cimento estão apresentados na Tabela 8.

\section{CONCLUSÕES}

Os resultados da atividade pozolânica com cimento (ABNT, 1992a) dos arenitos opalíferos da Serra do Itaqueri, representados pelas amostras TM100 e TM-101, apresentam índices entre 79 e 90\%, portanto bem acima do limite de $75 \%$ preconizado pela norma, caracterizando-os como pozolana natural. O resultado da amostra TM-100, entretanto, apesar de sua alta finura, encontra-se muito próximo do valor limite, sugerindo existir nela menor conteúdo de opala. A maior massa específica obtida pode também ser interpretada como um indicador da menor freqüência de opala entre as amostras, responsável pelo valor mais baixo de atividade pozolânica.

Os atributos intrínsecos dessas rochas, como os de natureza mineralógica, lito-estratigráfica ou 
TABELA 6: Proporções de componentes para preparação de argamassas para determinação da atividade pozolânica conforme NBR 5752/92.

\begin{tabular}{ccc}
\hline Material & Argamassa A (g) & Argamassa B (g) \\
\hline Cimento Portland & 312,0 & 202,8 \\
Material pozolânico & - & $109,2 \frac{\delta_{p o z}}{\delta_{\text {cim }}}$ \\
& & \\
Areia normal & 936,0 & 936,0 \\
Água & $\mathrm{X}$ & $\mathrm{Y}$ \\
\hline
\end{tabular}

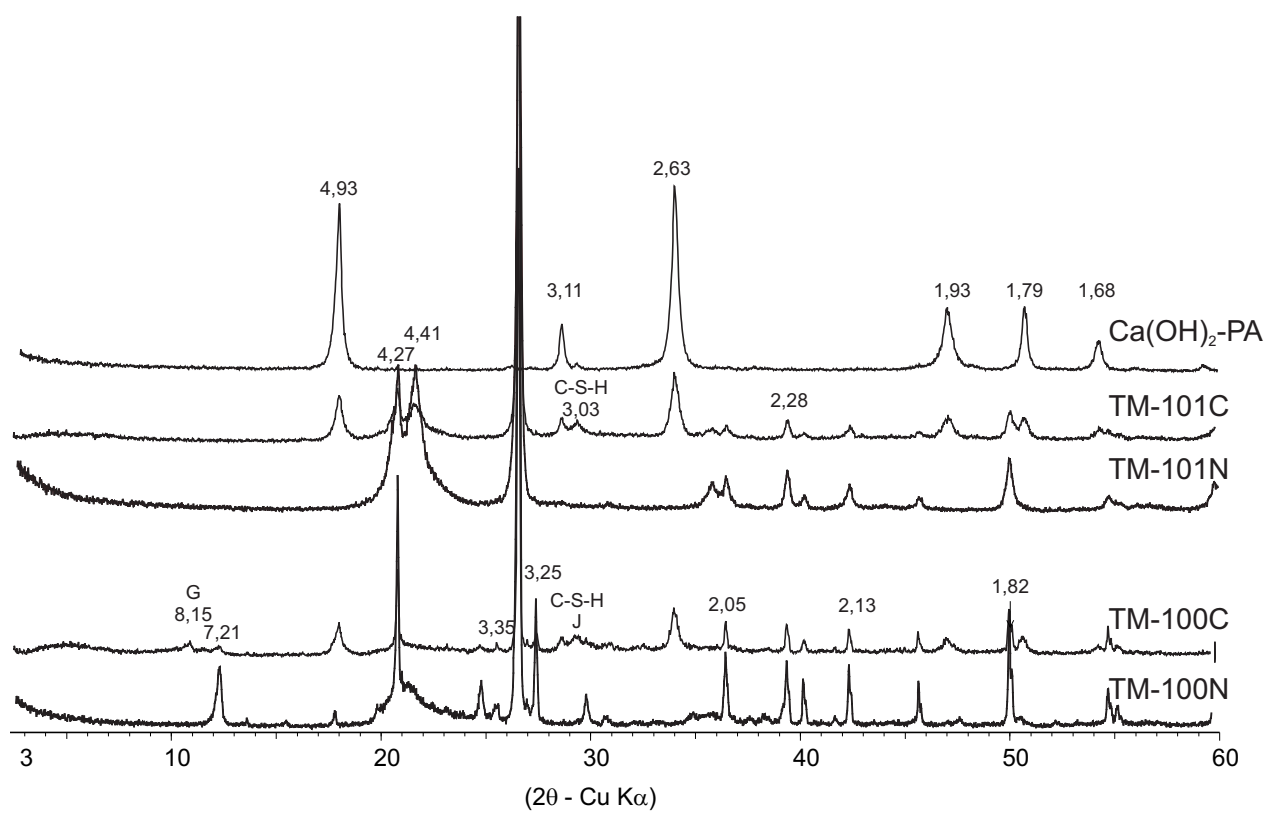

FIGURA 6: Difratogramas de raios X obtidos para amostra total de arenito opalino (amostra TM-100) e arenito silicificado (amostra TM-101) naturais; pastas de hidróxido de cálcio e arenitos após 7 dias (curada); e hidróxido de cálcio PA; C = curada; $\mathrm{N}$ = natural; $\mathrm{G}$ = girolita; $\mathrm{J}$ = jennita e C-S-H = hidróxido de cálcio hidratado.

tectônica, permitiram a elaboração de um modelo prospectivo factual para o tipo de depósito opalino que pode ser estendido para outras áreas da Bacia do Paraná. As ocorrências de arenitos silicificados mencionados por MEZZALIRA (1974) e COIMBRA et al. (1981), nas localidades de Rubião Júnior, Serra do Diabo, São Carlos e São Pedro, podem estar enquadrados sob o mesmo modelo.

O controle mineralógico da ocorrência de Itaqueri da Serra está associado aos compostos de sílica autigênica, representados, principalmente, por opala e calcedônia. Esses compostos cimentam os espaços intergranulares do arenito, ou ocasionalmente constituem a massa fundamental da rocha quando, então, ela se caracteriza petrograficamente como um "chert" opalino.

Admitindo-se que o alto topográfico onde afloram os arenitos opalinos seja sustentado exclusivamente por essas rochas, estima-se em $1 \times 10^{6} \mathrm{~m}^{3} \mathrm{o}$ volume de rocha mineralizada.

Por outro lado, se as indústrias cimenteira e de concreto reconhecem as qualidades tecnológicas excepcionais dos cimentos compostos e admitem muito pouca variabilidade na composição do cimento, elas colocariam os materiais pozolânicos, bem como os arenitos opalinos, na mira dos empresários que têm em mente a busca dos benefícios econômicos e ambientais. 
TABELA 7: Compostos neoformados na reação hidróxido de cálcio e arenito opalino, a partir da interpretação de difratogramas de raios $\mathrm{X}$.

\begin{tabular}{ccc}
\hline Amostra & $10^{\circ}$ a $11^{\circ}$ & Escala $2 \theta$ \\
\hline TM-100 curada & 1.girolita: & $29^{\circ}$ a $30^{\circ}$ \\
& $\mathrm{Ca}_{8} \mathrm{Si}_{12} \mathrm{O}_{30}(\mathrm{OH})_{4} \cdot 7 \mathrm{H}_{2} \mathrm{O}$ & 1.silicato de cálcio hidratado: \\
& & $\mathrm{Ca}_{2} \mathrm{SiO}_{4} \cdot \mathrm{H}_{2} \mathrm{O} ;$ \\
TM-101 curada & & 2.jennita: $\mathrm{Ca}_{9} \mathrm{H}_{2} \mathrm{Si}_{6} \mathrm{O}_{18}(\mathrm{OH})_{8} \cdot 6 \mathrm{H}_{2} \mathrm{O}$ \\
\hline
\end{tabular}

TABELA 8: Resultados de ensaios para determinação do índice de atividade pozolânica em amostras de arenito opalino (1 - Amostra; 2 - Massa específica $\left(\mathrm{g} . \mathrm{cm}^{3}\right) ; 3$ - Área específica $\left(\mathrm{cm}^{2} . \mathrm{g}^{-1}\right) ; 4$ - Resíduo na peneira de 45 mm (\%); 5 - Quantidade de água (g); 6 - Índice de atividade pozolânica com cimento - \%).

\begin{tabular}{cccccc}
\hline 1 & 2 & 3 & 4 & 5 & 6 \\
\hline TM-100 & 2,51 & 7.680 & 3,7 & 223,0 & 79 \\
TM-101 & 2,36 & 5.260 & 12,5 & 201,0 & 90 \\
\hline
\end{tabular}

A substituição de parte do clínquer Portland por material pozolânico contribui, significativamente, para a redução dos gases expelidos para a atmosfera, pois uma tonelada de calcário calcinado nos fornos rotativos expele $440 \mathrm{Kg}$ de $\mathrm{CO}_{2}$ (MONTANHEIRO 1999). Embora as normas brasileiras permitam a adição de até 50\% de material pozolânico em um cimento composto, ZAMPIERI (1993) pondera que a adição otimizada seria de $30 \%$.

Apesar de reconhecer que os custos de fabricação do cimento dependem de muitos fatores como, por exemplo, preço e tipo de energia, processo utilizado, tamanho da planta, incentivos fiscais regionais, tipo de cimento fabricado e outros, o consumo de energia elétrica está entre 100 - 200 kWh por tonelagem de cimento ou o equivalente a US\$9,00 US $\$ 11,00$ ( 1 US\$ = R \$2,30 e $1 \mathrm{kWh}=\mathrm{R} \$ 0,21031$ ).

Admitindo-se que os custos financeiros acrescidos dos custos da produção de pozolana natural figurem em torno de US\$3,00 por tonelada de minério, poder-se-ia juntar margem de lucro da ordem de $20 \%$ em um produto final com adição otimizada de pozolana.

\section{AGRADECIMENTOS}

À Fundação de Amparo à Pesquisa do Estado de São Paulo - FAPESP (processo 95-8815-3) e à Coordenação e Aperfeiçoamento do Pessoal de Nível Superior - CAPES pela liberação de recursos financeiros. À Márcia Mika Saito (IG-USP) e Luis
Antonio Teixeira (IG-SMA) pela confecção das ilustrações e ao Professor Jayme Antonio Montanheiro pela correção do texto. Expressamos os nossos agradecimentos aos relatores, cujas contribuições melhoraram o manuscrito.

\section{REFERÊNCIAS BIBLIOGRÁFICAS}

ACI COMMITTEE 232(WERNER II, O.R.) 1994. Use of natural pozzolans in concrete. ACI Materials Journal. Proposed report, 4:410-426.

AMARAL, G. 1977. Padrões fotogeológicos dos litofácies da Formação Bauru no Estado de São Paulo, como observados em imagens LANDSAT. In: SBG, Simpósio de Geologia Regional, 1, São Paulo, Atas. São Paulo, p.295302.

AMERICAN SOCIETY FOR TESTING AND MATERIALS (ASTM) 1985. Standard specification for fly ash and raw or calcined natural pozzolan for use as a mineral admixture in Portland cement concrete; C 618. In: American Society for Testing and Materials (ASTM) 1985. Annual book of ASTM standards. Philadelphia, v. 04.02, p. 382-385.

AMERICAN SOCIETY FOR TESTING AND MATERIALS (ASTM) 1997. ASTM C 595-M. Specification for blended hidraulic cement. Philadelphia, ASTM. 
ASSOCIAÇÃO BRASILEIRA DE NORMAS TÉCNICAS (ABNT) 1977. NBR 5751: Materiais pozolânicos - Determinação de atividade pozolânica - Índice de atividade pozolânica com cal, 3p.

ASSOCIAÇÃO BRASILEIRA DE NORMAS TÉCNICAS (ABNT) 1984. NBR - 6474. Determinação da massa específica.

ASSOCIAÇÃO BRASILEIRA DE NORMAS TÉCNICAS (ABNT) 1991. NBR -5736/91. Cimento Portland pozolânico.

ASSOCIAÇÃO BRASILEIRA DE NORMAS TÉCNICAS (ABNT) 1991. NBR - 11579/91. Determinação da finura por meio da peneira $75 \mu \mathrm{m}$ $\left(\mathrm{n}^{\circ} 200\right)$.

ASSOCIAÇÃO BRASILEIRA DE NORMAS TÉCNICAS (ABNT) 1992. NBR - 12653: Materiais pozolânicos, 3p.

ASSOCIAÇÃO BRASILEIRA DE NORMAS TÉCNICAS (ABNT) 1992. NBR - 5751/92. Materiais pozolânicos - Determinação da atividade pozolânica - Índice de atividade pozolânica com cal, 3p.

ASSOCIAÇÃO BRASILEIRA DE NORMAS TÉCNICAS (ABNT) 1992. NBR - 5752/92. Materiais pozolânicos - Determinação da atividade pozolânica com cimento Portland - Índice de atividade pozolânica com cimento, 3p.

ASSOCIAÇÃO BRASILEIRA DE NORMAS TÉCNICAS (ABNT) 1996. NBR 7224. Determinação da área específica, 7p.

BÓSIO, N.J. 1972. A Formação Botucatu na região de São Pedro, SP. In: SBG, Congresso Brasileiro Geologia, 26, Belém, Resumos, p.249-250.

COIMBRA,A.M.; BRANDT NETO, M.; COUTINHO, J.M.V. 1981. Silicificação dos arenitos da Formação Bauru no Estado de São Paulo. In: SBG, A Formação Bauru no Estado de São Paulo e Regiões Adjacentes, São Paulo. Coletânea de trabalhos e debates, p. 103-115.

KITSOPOULOS, K.P. \& DUNKAM, A.C. 1996. Heulandite and mordenite-rich tuffs from Greece: a potential source for pozzolanic materiais. Mineralium Deposita, 31(6):576-584.
MALQUORI, G. 1960. Portland-Pozzolan Cement. In: International Symposium on the Chemistry of Cement, 4, Washington, D.C, Paper VIII-3, 2:983-1006.

MASSAZZA, F. 1976. Chimica delle aggiunte pozzolaniche e dei cementi di miscela. Il Cemento, 73(1):3-38.

MEHTA, K. 1987. "Natural Pozzolans." Supplementary Cementing Materials for Concrete, CANMET-SP-86-8e, Canadian Government Pubblishing Center, Supply and Services, Ottawwa.V1, p. 1-33.

MELO, M.S. 1995. A Formação Rio Claro e depósitos associados: sedimentação neocenozóica na depressão periférica paulista. Instituto de Geociências, Universidade de São Paulo, São Paulo. Tese de Doutoramento, 144p.

MEZZALIRA, S. 1974. Contribuição ao conhecimento da Estratigrafia e Paleontologia da Formação Bauru. Boletim IGG, no. 51.

MIELENZ, R.C.; Greene, K.T. \& Schieltz, N.C. 1951. Natural pozzolans for concrete. Economic Geology, 46:311-328.

MILANI, E.J. 1997. Evolução tectono-estratigráfica da Bacia do Paraná e seu relacionamento com a geodinâmica fanerozóica do Gondwana SulOcidental. Instituto de Geociências, Universidade Federal do Rio Grande do Sul, Porto Alegre, Tese de Doutoramento, 255p.

MONTANHEIRO, T.J. 1999. Prospecção e caracterização de pozolanas na Bacia do Paraná, Estado de São Paulo. Instituto de Geociências, Universidade de São Paulo, São Paulo, Tese de Doutoramento, 226p.

PONÇANO, W.L.; STEIN, D.P.; ALMEIDA, F.F.M.; ALMEIDA, M.A.; MELO, M.S. 1982. A Formação Itaqueri e depósitos correlatos no Estado de São Paulo. In: Congresso Brasileiro Geologia, 32, Salvador, Anais, 4:339-1350.

RICCOMINI, C. 1995. Tectonismo gerador e deformador dos depósitos sedimentares pósgondvânicos da porção centro-oriental do Estado de São Paulo e áreas vizinhas. Instituto de Geociências, Universidade de São Paulo, São Paulo, Tese de Livre-Docência, 100p. 
RICCOMINI, C. 1997. Considerações sobre a posição estratigráfica e tectonismo deformador da Formação Itaqueri na porção centro-leste do Estado de São Paulo. Revista do Instituto Geológico, 18:441-448.

YAMAMOTO, J.K.; KIHARA, Y.; COIMBRA, A.M.; MONTANHEIRO, T.J.1997. Enviromental impact reduction on the prodution of blended Portland cemet in Brazil. Environmental Geosciences, 4:192-206.
ZAMPIERI, V.A. 1993. Cimento Portland aditivado com pozolanas de argilas calcinadas: fabricação, hidratação e desempenho mecânico. Instituto de Geociências, Universidade de São Paulo, Tese de Doutoramento. 233p.

\section{Endereço dos autores:}

Tarcísio José Montanheiro: Instituto Geológico, Secretaria do Meio Ambiente do Estado de São Paulo. Avenida Miguel Stéfano, 3900 - CEP 04301-903 - Água Funda, São Paulo/SP. E-mail: tjmonta@igeologico.sp.gov.br

Jorge Kazuo Yamamoto/Yushiro Kihara: Instituto de Geociências, Universidade de São Paulo. Rua do Lago, 562 - CEP 05508-900 - Cidade Universitária, São Paulo/SP. 